Andrew Salway and Khurshid Ahmad

"Multimedia Systems and Semiotics: Collateral Texts for Video Annotation"

Procs. IEE Colloquium Digest, Multimedia Databases and MPEG-7, pp.7/1-7/7. ISSN/ISBN 0963-3308. 


\section{MULTIMEDIA SYSTEMS AND SEMIOTICS: COLLATERAL TEXTS FOR VIDEO ANNOTATION}

Andrew Salway and Khurshid Ahmad*

\begin{abstract}
Multimedia content can be described at different levels of abstraction such as measures of video colour, texture and motion and comparatively highlevel 'semantic' descriptions in textual form. The textual description of moving images at different levels of abstraction can be explored in the context of moving images from a specialist domain, such as sequences of dance. The $\mathrm{KAB}$ system annotates video using collateral texts about dances produced by experts. The analysis of dance, by experts, is grounded in theories of aesthetics and semiotics: the potential contribution of such theories to a framework for multimedia computing is discussed.
\end{abstract}

\section{Introduction}

The retrieval of a part or the whole of a moving image from a systematically organised collection depends upon how each moving image, and parts of each, are described. In order that images can be accessed across different systems, by many people, and for a variety of purposes, it is necessary to attach descriptions to them, following a well developed scheme. The MPEG-7 standard is being developed to provide a description definition language from which description schemes and descriptors can be specified [1].

Descriptors may comprise colour, texture and motion information about moving images - a low level abstraction. Alternatively, descriptors may be text strings which are implicitly loaded with meaning - for example, a dance sequence can be analysed in terms of sophisticated movements like plié, pirouette and rond de jambe. Such terms convey detailed information about the moving image which one may construe as a high-level description. Traditional information retrieval can, in principle, be used to index, and subsequently retrieve, moving images labelled with such terms. Image and video database systems may use both low and high-level descriptors [2]; in some cases the high-level descriptors are derived from textual information occurring in video, like speech and subtitles [3].

The analytical delineation of levels of image description is important since research problems at low, high and intermediate levels are complex. Fischler and Firschein proposed the phrase 'signal to symbols paradigm' to characterise how research in computer vision addresses this range of levels [4]. However, whilst much research in computer vision and image indexing has addressed low-level image analysis, there is perhaps a need for frameworks in which higher-level, conceptual descriptions of visual information can be produced [5].

For us, the discussion about how to describe high-level visual information in abstract and schematic ways should be grounded in two respects. First, we should choose exemplar images that are aesthetically interesting and highly stylised. Second, there should be an archive of texts, produced by experts, that elucidate these images in depth. The phrase 'collateral text' may be used to refer to such descriptions and interpretations of moving images, extending its previous use of denoting newspaper photograph captions [6].

Moving images of dance are both aesthetically interesting and highly stylized. Furthermore, when speaking and writing about dance sequences, experts can analyse them at different levels of abstraction. This paper describes how knowledge-rich content descriptions of dances were obtained from experts and used to annotate and subsequently browse a digital video library of dance.

\footnotetext{
* Dept. of Computing, University of Surrey, UK.

a.salway/k.ahmad@surrey.ac.uk
} 


\section{Aesthetics and semiotics of moving images}

Dancers and dance scholars provide interesting images and symbol systems for investigating video annotation. Dance scholars can describe the dancing body in terms of its parts, or as a part of a greater whole - when groups of dancers form patterns. An analysis of a dance might classify it in terms of its genre, or may focus on short, but significant sequences to analyse in detail. At various stages in an analysis the movements of the dance may be described, possibly with the aid of a movement notation system, and interpreted - to explicate the significance of movements and the narrative of the dance. In both cases dance experts write and talk about moving images with a minimum of redundancy whilst innovating new descriptions for previously unseen movements. Their analyses appear in a variety of types of text including dance previews, reviews, journal articles and textbooks.

Typically, those involved in the analysis of moving images, either in the context of film, like Christian Metz [7], or in the context of dance, like Janet Adshead [8], have discussed these images both in relation to a generic description of their contents and a specific description. Further, moving images are discussed in terms of their 'aboutness' at a more abstract level.

For instance, Metz describes images at the physical level - where visual phenomena become perceptually meaningful as generic contents; the diegetic level - which comprises the specific 4D spatio-temporal world posited by the moving image; and the connotative and sub-textual levels in which the aboutness of moving images is conveyed by metaphorical meanings and specialised symbols. Adshead's analysis of dance is also at four levels, description of movements, discernment of form, interpretation and evaluation. Here the description of movements relates to the level of generic contents; the grouping of these elements into forms relates to the specific contents; and the aboutness of the dance is explicated by interpretation and evaluation.

The work of Metz and of Adshead can be related to earlier work on images, albeit still images, by the art scholar Erwin Panofsky [9]. For Panofsky, the three levels of meaning in a painting were: the preiconographic, comprising the generic contents, e.g. a man in a city; the iconographic, forming the specific contents, e.g. a particular man in a particular city; and the iconological, that is what the painting is about, e.g. politics, war, peace.
The frameworks of Panofsky, Metz and Adshead are presented in Table 1. Note that there is a fifth level of contents discussed by Metz which is of relevance to the description of video: this relates to cinematic features such as cuts, pans and zooms - it is not included in Table 1 as it has no analogue in the realms of paintings or dance. (Lindley and Srinivasan [10] have described the work of Metz in some detail as the basis of a video generation system; Shatford [11] proposed the use of Panofsky's framework as the basis for organising picture collections).

Table 1: Frameworks for the analysis of images.

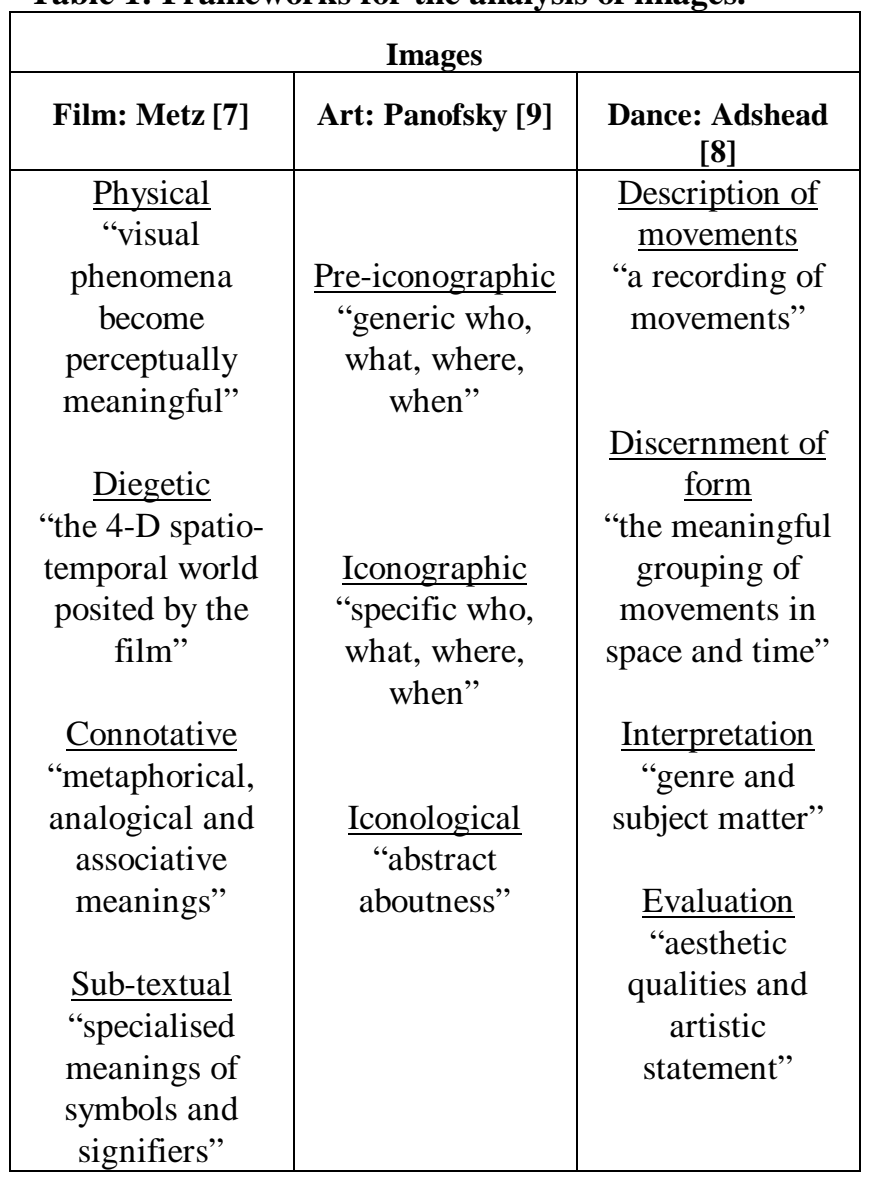

\section{Knowledge-rich Video Annotation}

In order to study how video can be annotated with textual information, an investigative method has been developed in which an expert 'thinks out loud' whilst viewing a moving image. This method is based on Protocol Analysis [12] and assumes that an expert's verbalization reflects their cognitive activity when perceiving and understanding the moving image. When transcribed, the verbalization, or 'commentary', is a symbolic expression of some of the video's contents - based on the expert's knowledge and aligned in time with the video. There are different aspects of video content which an expert 
can talk about, but only one speech channel available to them. The experts can be guided by instructions to focus on different contents of the video according to the levels of analysis in Table 1.

Five dance experts twice watched 20 minutes of dance video (comprising excerpts from four dances). They were first given an instruction to 'Describe' the dance; on the second viewing they were asked to 'Interpret' (see Table 1 for this distinction). To date, 38 (out of 50) commentaries have been transcribed with timecodes attached to each speech fragment ( 25 texts from the 'Describe' task, 11,300 words; and 13 texts from the 'Interpret' task, 6,289 words).

Dance experts have at their disposal a specialist vocabulary with which to describe dance. An analysis of the commentaries showed that 14 terms present in Koegler's Concise Oxford Dictionary of Ballet were used by experts in the 'Describe' task. Some of these refer to positions held by dancers, arabesque (22 occurrences) and attitude (24); some to general kinds of movement adagio (1) - slow, and batterie (1) - with beating legs; and others to particular types of movement, pirouette (6) - turning on one leg with foot touching knee; and, promenade (1) - turning slowly with body held in a set position.

Definitions of these specialist terms can be given in the form of movement notation, such as the Labanotation system, Fig. 1.

Fig. 1: Labanotation definitions for two forms of pirouette - en attitude and en arabesque. (From The Gail Grant Dictionary of Classical Ballet in Labanotation).

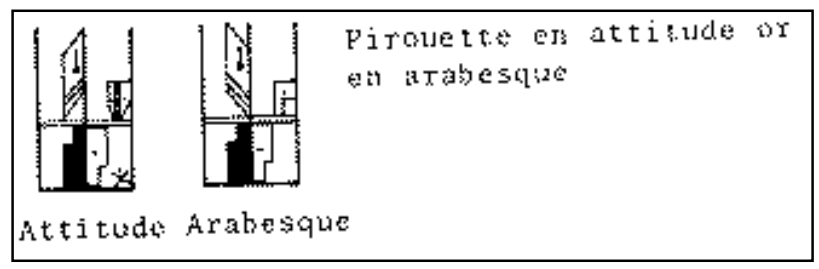

Labanotation is read from bottom to top. Symbols to the left of the centre refer to movements made by the left foot, leg, torso, arm, hand and head - in that order. The symbols' points, shadings and sizes represent the movement dynamics of direction, level of extension and duration.

In the Concise Oxford Dictionary of Ballet specialist dance terms, like pirouette, are explained in general language:

\begin{abstract}
Pirouette (Fr., spinning-top). Designates in ballet one or more turns of the body on one leg (on half or full point), with the point of the working leg generally touching the knee of the supporting leg. It can be executed à la seconde, en attitude, en arabesque, or sur le coup-de-pied.
\end{abstract}

The dictionary entry notes that they are various forms of pirouette, including en attitude. The definition for attitude gives more detail about body position and some historical information:

Attitude (Fr.). A position of the body
inspired by Giovanni da Bologna's statue of
Mercury, and codified by Blasis. The body is
supported on one leg with the other behind, the
knee bent at an angle of $90^{\circ}$, turned out, with
the knee higher than the foot.
corresponding arm is raised above the head,
while the other arm is extended to the side.
The various national schools have developed
different variants. It can be executed in
several ways: relevée, sautée, en tournant en
avant (or en arrière), effacée, croisé, etc.

Definitions of specialist dance terms include movement words from general language. Thus, pirouette is a particular type of turn (or to pirouette is to turn in a particular kind of way). Doing a pirouette involves other actions - a leg supporting the body and the touching of a knee with a foot. The pirouette can be executed in a number of ways, including en attitude - in which case one arm will be raised above the head and the other extended to the side.

General language words for describing the positions and movements of the human body, were prominent in the commentaries elicited from the dance experts. The 100 most frequent words used in the 'Describe' and 'Interpret' tasks (excluding closed class words) are shown in Tables $2 \mathrm{a}$ and $2 \mathrm{~b}$ respectively. 
Table 2a: 100 most frequent words used in the 'Describe' task (excluding closed class words) : note that the words in each cell are in frequency order.

\begin{tabular}{|l|l|}
\hline $\begin{array}{l}\text { Dancers, } \\
\text { bodies and } \\
\text { surroundings }\end{array}$ & $\begin{array}{l}\text { man, arms, character, swan, hands, dancers, } \\
\text { leg, arm, head, male, floor, body, dancer, } \\
\text { foot, female, hand, stage, women, } \\
\text { background, heads, partner, shoulder, } \\
\text { person, swans, figure, chest, bodies, couple, } \\
\text { neck }\end{array}$ \\
\hline $\begin{array}{l}\text { Movements } \\
\text { and positions }\end{array}$ & $\begin{array}{l}\text { position, moving, movement, movements, } \\
\text { standing, holding, balance, turns, turn, } \\
\text { turning, jumps, going, jumping, attitude, }\end{array}$ \\
& $\begin{array}{l}\text { lying, steps, supporting, kneeling, walking, } \\
\text { gesture, circle, motif, positions, action, }\end{array}$ \\
arabesque, looking, goes, lifting, twisting, \\
touching, plié, gestures, duet, balancing, \\
following, leaps, facing, bent, shaking, \\
point, move, jump, spins, stroking, holds, \\
sitting, moves, walks, contact, lifted, come, \\
leans \\
\hline Movement \\
slow, little, big, unison, slowly, extended, \\
quick, small, gestural, flexed, sustained, \\
lyrical
\end{tabular}

Table 2b: 100 most frequent words used in the 'Interpret' task (excluding closed class words) : note that the words in each cell are in frequency order.

\begin{tabular}{|l|l|}
\hline $\begin{array}{l}\text { Dancers, } \\
\text { bodies \& } \\
\text { surroundings }\end{array}$ & $\begin{array}{l}\text { swan, man, male, character, dancers, swans, } \\
\text { people, arms, men, prince, woman, female, } \\
\text { bodies, body, dancer, leg, wings, moon, } \\
\text { hand, hands, birds, background, floor, group, } \\
\text { stage, heads, women, figure }\end{array}$ \\
\hline $\begin{array}{l}\text { Movements } \\
\text { and positions }\end{array}$ & $\begin{array}{l}\text { movement, movements, looking, moving, } \\
\text { supporting, touching, duet, support, unison, } \\
\text { holding, coming, going, gesture, action, } \\
\text { circle, lifting, move, point, position, } \\
\text { stillness, manipulating, leaving, comes, } \\
\text { moves, come, dance, standing, twisting, } \\
\text { picking, flight, solo, lying, reaching, trying, } \\
\text { curve, contact, dancing, following, lifted, } \\
\text { pulling }\end{array}$ \\
\hline Movement & $\begin{array}{l}\text { strong, strength, formal, caring, } \\
\text { independently, enjoying, physical, slowly, } \\
\text { aggressive, longing, little, slow, gentle, } \\
\text { gestural, religious, underwater }\end{array}$ \\
\hline Other & $\begin{array}{l}\text { relationship, sense, images, idea, suggesting, } \\
\text { important, fantasy, suggests, significant, } \\
\text { camera, presence, exist, significance, roles, } \\
\text { references, lake }\end{array}$ \\
\hline
\end{tabular}

These results show a range of terms with which an expert can analyse a dance sequence by extracting salient patterns of movement. The terms include specialist terms like arabesque and plié and general language terms like turns, jumps, and spins. The relative frequency of terms might indicate where the focus of the experts' attentions lie when they analyse dance, for example arms and hands are more frequent than legs and feet.
The contrasting contents of Tables $2 a$ and $2 b$ perhaps reflects the differences between the level of generic contents (elicited by the 'Describe' task) and the level of metaphoric and associated meanings (elicited by the 'Interpret' task). In the case of Table $2 \mathrm{~b}$, words like prince and wings are being used as well as man and arms to refer to the dancers; movements include flight and manipulating; and the movement qualities are more expressive e.g. aggressive and gentle - there are also suggestions of movement having a religious quality and looking like it is happening underwater.

\section{The KAB System}

The KAB system (Knowledge-rich Annotation and Browsing) has been developed to analyse collateral texts alongside digital video, combining automatic techniques for text analysis with a video database following that of [13]. Texts analysis techniques are used to generate lists of candidate terms for annotation, from experts' commentaries and extant written texts. Video objects in the form \{start time: end time: term $\}$ are generated from time-coded transcripts and organised term lists to annotate the video, Fig.2. The video collection is browsed through the same lists of terms. The system currently attaches video objects to sequences of frames: with the prospect of object-based video coding (e.g. MPEG-4) it will be important to study how annotations can be attached to particular entities in the video, e.g. dancers. 


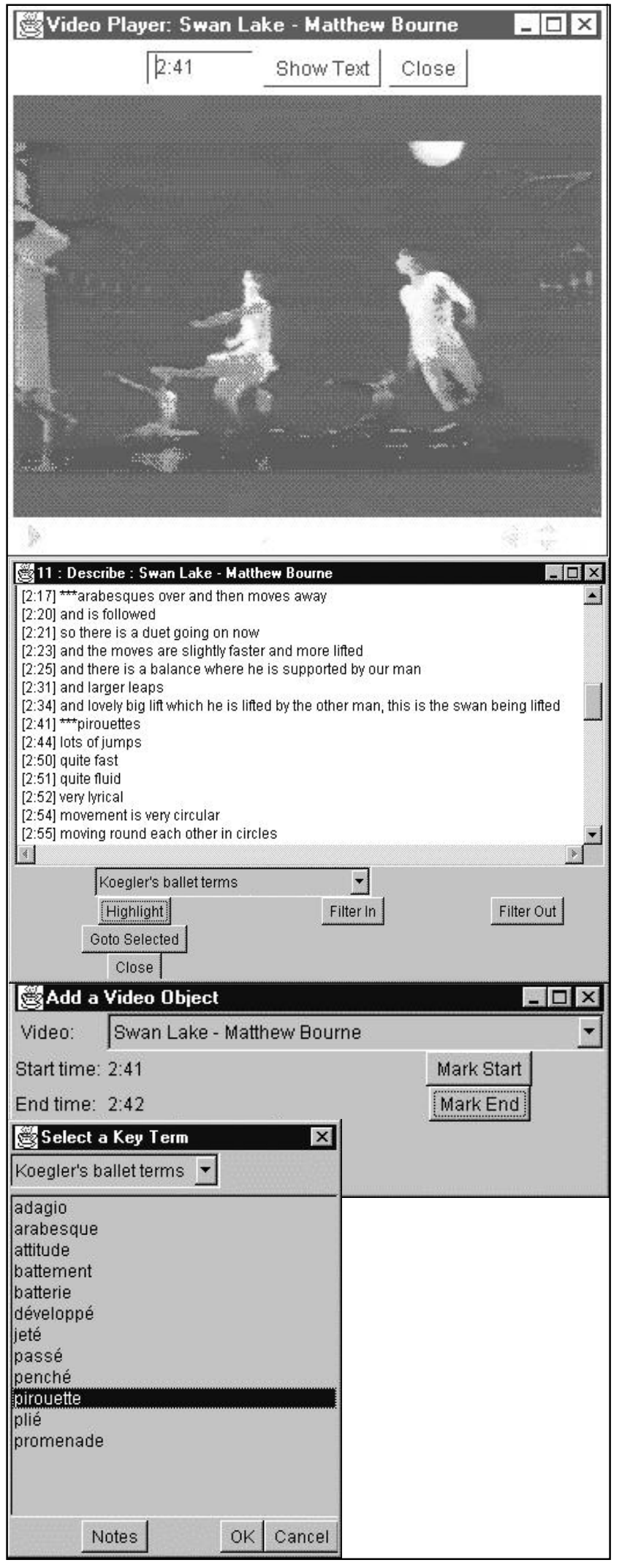

Fig. 2: Video annotation in KAB. KAB highlights (with $* * *$ ) the term pirouette in the collateral text. A video object is created with start and end times.

\section{Discussion and closing remarks}

\section{Collateral texts for video annotation}

The analysis of experts' terms shows how they can be rich in meaning, compared to say a movement notation: this perhaps supports the use of textual descriptions for video annotation. However the approach has received relatively little attention in multimedia systems research. This may be due to three reasons: (i) the diverse ways in which visual information can be perceived and understood makes human descriptions unwieldy in a formal computational context; (ii) human involvement in the indexing process introduces subjectivity; (iii) the cost of human resources for indexing large quantities of visual information.

With regards to point (i), multimedia research can perhaps adapt frameworks from aesthetic fields for organising descriptions of image and video content. Variance in annotation due to human subjectivity will perhaps be less likely when dealing with experts in specialist domains who have established methods for analysing images: we found that this seemed to be the case when looking at commentaries of the same dance elicited from different experts. As for the expense of manual indexing methods, it should be noted that there may be cases in which lengthy and expensive manual indexing effort is economical because it allows many people to access information effectively. Methods should nevertheless aim to minimise levels of human input by integrating automated image analysis processes.

\section{Aesthetics and semiotics for multimedia systems}

The creation of a description definition language may be seen as akin to the creation of a metalanguage: perhaps then, multimedia research can benefit from the work of scholars in aesthetics and semiotics who have investigated the 'Languages of Art' [14], 'Film Language' [7], 'The Languages of Images' [15] and 'The Search for the Perfect Language' [16]. We have previously suggested that research in multimedia computing can share a symbiotic relationship with research in aesthetics and semiotics, such as that shared between research in natural language processing and linguistics [17].

Others have also made cases for grounding various aspects of multimedia computing research in semiotic frameworks. Some of these viewpoints emphasise the syntactic properties of the multimedia document: the semiotic terminology of Charles 
Sanders Peirce has been used in a model of media objects that reflects the nature of different signs, their modality and the ways they are arranged to achieve communication [18]. According to another researcher, who discusses the semiotic theory of Charles Morris, 'generating suitable data models for hypermedia requires the identification of the semiotic articulation in multimedia data' [19].

In contrast, some proposals have emphasised the importance of studying the production and understanding of multimedia artefacts: a study of video production was guided by the work of a film theorist, Dudley Andrew [20]; and the understanding of multimedia information has been discussed in relation to Umberto Eco's ideas regarding the 'Role of the Reader' [21]. The importance of considering the purposes for which multimedia documents are created has also been noted, with reference to three types of text delimited by Seymour Chatman, 'description', 'argument' and 'narrative': this classification motivated a structure for hypermedia documents [22].

The domains of aesthetics and semiotics are broad and have long histories. The applicability of analytic frameworks for characterising 'levels of abstraction' for multimedia information was described in this paper. Examining the potential contribution of aesthetic and semiotic theories to video annotation is part of our ongoing research [23]. Of particular interest are (i) theories which seek to untangle definitions of media and modes [24]; (ii) theories which explore how the understanding of a text depends on networks of related texts known by the reader, the so-called phenomenon of 'intertextuality' [25]; and (iii) theories which discuss the differences between visual and verbal communication and suggest how images and words can be related [26].

\section{References}

[1] MPEG-7 (1998). 'MPEG-7 Context and Objectives'. ISO/IEC JTC1/SC29/WG11 N2460, MPEG/98, October 1998/Atlantic City, USA.

[2] Flickner, M. et al. (1997). 'Query by Image and Video Content: The QBIC System.' In: Maybury, M. (ed.), Intelligent Multimedia Information Retrieval, pp. 7-22. Menlo Park CA: AAAI Press / MIT Press.

[3] Christel, M. et al. (1996). 'Techniques for the Creation and Exploration of Digital Video Libraries.' In: Furht, B. (ed.) Multimedia Tools and Applications, pp. 283-327. Boston: Kluwer Academic Publishers.

[4] Fischler, M. and Firschein, O. (1987). Intelligence: The Eye, the Brain and the Computer. Reading MA: AddisonWesley.
[5] Nagel, H.-H. (1988). 'From Image Sequences Towards Conceptual Descriptions.' Image and Vision Computing 6, pp. 59-74.

[6] Srihari, R. (1995). 'Use of Captions and other Collateral Text in Understanding Photographs.' Artificial Intelligence Review 8 (5-6), pp. 409-430.

[7] Metz, C. (1974). Film Language: a semiotics of the cinema. New York: Oxford University Press.

[8] Adshead, J. (1988 ed.). Dance Analysis: theory and practice. London: Dance Books.

[9] Panofsky, E. (1970/1955). Meaning in the Visual Arts. Harmondsworth: Penguin.

[10] Lindley, C. and Srinivasan, U. (1998). 'Query Semantics for Content-Based Retrieval of Video Data: an Empirical Investigation.' To appear: Procs. Storage and Retrieval Issues in Image and Multimedia Databases, DEXA98, Vienna.

[11] Shatford, S. (1986). 'Analyzing The Subject of a Picture: A Theoretical Approach', Cataloging and Classification Quarterly, 6 (3), pp. 39-62.

[12] Ericsson, K. A. and Simon, H. A. (1993). Protocol Analysis: Verbal Reports as Data. Cambridge MA and London: The MIT Press.

[13] Oomoto, E. and Tanaka, K. (1993). 'OVID: Design and Implementation of a Video-Object Database System.' IEEE Trans. Knowledge and Data Engineering 5 (4), pp. 629-643.

[14] Goodman, N. (1976). Languages of Art. Indianapolis / Cambridge: Hackett Publishing Co.

[15] Mitchell, W. J. T. (1980, ed.). The Language of Images. Chicago and London: Chicago University Press.

[16] Eco, U. (1995). The Search for the Perfect Language. Oxford, UK and Cambridge, USA: Blackwell.

[17] Ahmad, K., Salway, A. and Adshead-Lansdale, J. (1998). 'The Moving (Human) Image and its Annotation'. Submitted to Image and Vision Computing.

[18] Purchase, H. (1998). 'Defining Multimedia', IEEE Multimedia Jan-March 1998, pp. 8-15.

[19] Gonzalez, R. (1997). 'Hypermedia Data Modeling, Coding, and Semiotics', Proc. IEEE 85 (7), pp. 1111-1140.

[20] Minneman, S. L. and Smoliar, S. W. (1996). 'Representing the Content of Video: Artifact or Process?' In: Procs. Knowledge Representation for Interactive Multimedia Systems: Research and Experience. (Budapest, Hungary, August 1996), ECAI, pp. 57-65.

[21] Smoliar, S. W. et al. (1996). 'Multi-Media Search: an authoring perspective.' In: Smeulders, A. and Jain, R. (eds.), Image Databases and Multi-Media Search, pp. 1-8. Singapore: World Scientific.

[22] Smoliar, S. W. and Baker, J. D. (1997). 'Text Types in Hypermedia.' In: Procs. Thirtieth Annual Hawaii International Conf. on System Sciences. (Wailea, Hawaii, January 1997), Volume VI, pp. 68-77.

[23] Salway, A. (1999). Video Annotation: the role of specialist text. Forthcoming Ph.D. thesis, Dept. of Computing, University of Surrey, UK.

[24] Hess-Lüttich, E. W. B. (1982 ed.). Multimedial Communication, Vol. I: Semiotic problems of its notation. Tübingen: Gunter Narr Verlag.

[25] Worton, M. and Still, J. (1990). Intertextuality: theories and practices. Manchester: Manchester University Press.

[26] Mitchell, W. J. T. (1994). Picture Theory: Essays on Verbal and Visual Representation. Chicago and London: Chicago University Press. 